\title{
High-fidelity simulation in the nonmedical domain: practices and potential transferable competencies for the medical field
}

This article was published in the following Dove Press journal:

Advances in Medical Education and Practice

19 May 201I

Number of times this article has been viewed

\author{
Pierre-Nicolas Carron \\ Lionel Trueb \\ Bertrand Yersin \\ Emergency Service, University \\ Hospital Center, Lausanne, \\ Switzerland
}

Correspondence: Pierre-Nicolas Carron

Emergency Service, University

Hospital Center, BH 06-428, CHUV

I0II Lausanne, Switzerland

$\mathrm{Tel}+4 \mid 2$ I3 I 43894

Fax $+4 \mid 2$ I 3 I 45590

Email pierre-nicolas.carron@chuv.ch

\begin{abstract}
Simulation is a promising pedagogical tool in the area of medical education. High-fidelity simulators can reproduce realistic environments or clinical situations. This allows for the practice of teamwork and communication skills, thereby enhancing reflective reasoning and experiential learning. Use of high-fidelity simulators is not limited to the medical and aeronautical fields, but has developed in a large number of nonmedical organizations as well. The techniques and pedagogical tools which have evolved through the use of nonmedical simulations serve not only as teaching examples but also as avenues which can help further the evolution of the concept of high-fidelity simulation in the field of medicine. This paper presents examples of high-fidelity simulations in the military, maritime, and aeronautical fields. We compare the implementation of high-fidelity simulation in the medical and nonmedical domains, and discuss the possibilities and limitations of simulators in medicine, based on recent nonmedical applications.
\end{abstract}

Keywords: high-fidelity simulation, crew resource management, experiential learning

\section{Introduction}

Simulation is currently a burgeoning pedagogical tool in the area of medical education, including in pregraduate, postgraduate, and continuing education. Simulation allows for the reconstitution of all or part of real-life situations in order to improve understanding as well as gain specific competencies. The concept of simulation encompasses a variety of possibilities, ie, simple "task-trainers" that allow training for specific tasks, high-fidelity simulations that reproduce an interactive and extremely realistic environment or clinical situation of a patient, or standardized simulated patients that allow for the practice of communication skills. High-fidelity mannequin-based simulations allow for training of an individual or a team under virtual conditions as close to a real situation as possible. ${ }^{1,2}$ Use of video and systematic, structured debriefing enhance reflective reasoning and experiential learning. ${ }^{3,4}$

Use of simulators has by no means been limited to the medical and aeronautical fields, but has developed in a good number of nonmedical organizations as well. The techniques and pedagogical tools which have evolved through the use of simulations serve not only as teaching examples but also as avenues which can help further the evolution of the concept of high-fidelity simulation in the field of medicine.

\section{Simulation in the aeronautical field: the precursors}

Aeronautics is without a doubt the precursor in the area of simulation and teamwork. In 1978, the National Aeronautics and Space Administration began studies on human 


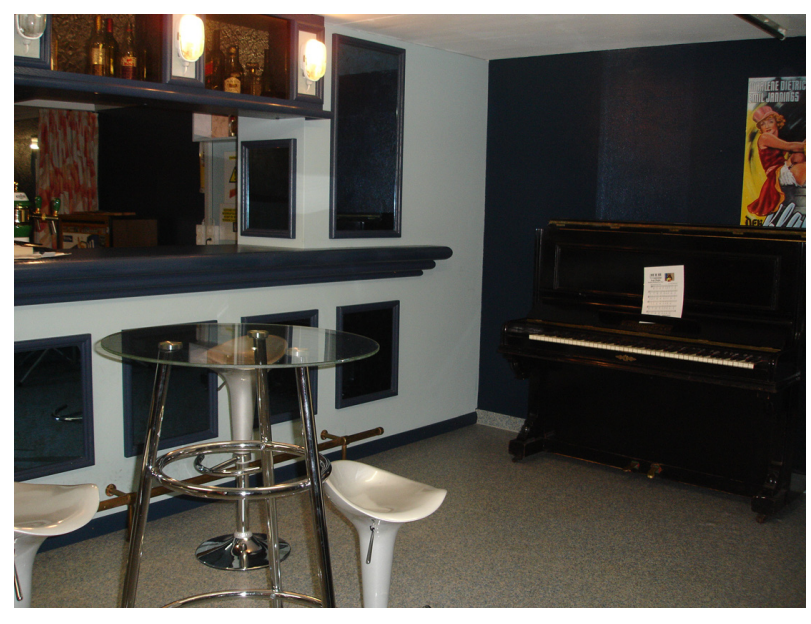

Figure I Simulation of a crime scene in a discotheque (@ Police Academy of Savatan Robin Uldry).

resource management and found that most aviation accidents involved factors such as lack of leadership, coordination, or decision-making. The National Transportation Safety Board later developed the Cockpit Resource Management module which is based on group dynamics, leadership, and decisionmaking processes. ${ }^{5}$ By the end of the 1980 s, the concepts of "teamwork" and "cockpit resource management" were widespread among Western airline companies and became the official standard recommended by the International Civil Aviation Organization for all commercial airlines. In 1986, “cockpit resource management" was renamed "crew resource management" (CRM) to reflect its extension to all flight personnel, and includes additional notions such as stress management and information-sharing. ${ }^{6}$

The concept of high-fidelity simulation is intimately tied to the development of the aforementioned concepts, with simulators reproducing the instrumentation, environment, and conditions in an airplane cockpit (ie, flight simulation training devices). ${ }^{6}$ Teams are trained to deploy emergency

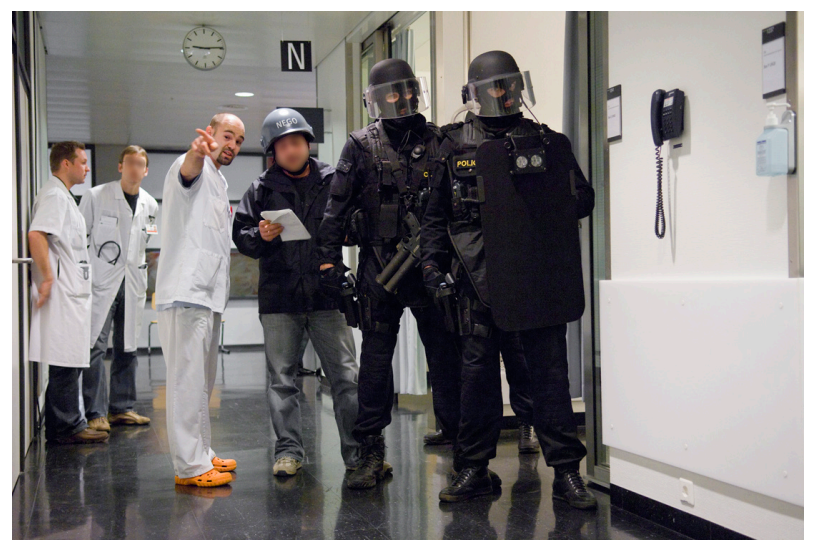

Figure 2 Simulation of a hostage situation organized in the emergency service (C CEMCAV-CHUV, Willy Blanchard).
Table I Crew resource management components ${ }^{5,6}$

- Situational awareness

- Self-awareness

- Planning

- Decision-making

- Communication

- Leadership

- Emotional climate

- Stress management

- Assertiveness training

procedures, practice approaches, and master atypical environments or situations, eg, electric or hydraulic breakdowns, and breakdowns of navigational instruments. In addition, the use of simulation allows for team training in flight procedures with minimal costs and environmental impact.

\section{Civil maritime navigation: realistic safety training}

Application of the concepts of teamwork and CRM in the domain of civil maritime navigation evolved naturally, not only because of the inherent similarities between aviation and maritime navigation (working in teams, a hierarchical structure), but also because of the frequency of human errors recorded in reports of maritime accidents. ${ }^{7}$ Variants of the Flight Management Attitude Questionnaire were used to analyze the behavior of Danish, Philippine, and Indian mariners, and showed that the at-risk behaviors were similar to those of commercial flight crews, ie, underestimation of stress and fatigue, overestimation of abilities, and feelings of invulnerability. ${ }^{7,8}$

These elements led to the development of the maritime crew resource management training and bridge resource management modules, which tied together the concepts of human error, CRM, and high-fidelity simulation. ${ }^{7}$ The main emphasis is on human behavior, team management in emergency situations, and the establishment of optimal and

Table 2 Benefits of simulation sessions $s^{1,2,34,35}$

\footnotetext{
- Teach knowledge and procedures

- Crew resource management

- Teach behaviors

- Improve communication

- See yourself at work

- Practice without risk

- Practice at lower costs

- Experience and repeat uncommon situations

- Practice use of equipment

- Experience alternative conditions and courses of actions

- Evaluate different actions in identical scenarios

- Transfer of training to real situation
} 
Table 3 Transferable competencies for medical education and training $34,38,39$

\begin{tabular}{|c|c|c|}
\hline Domain & Important concepts & $\begin{array}{l}\text { Examples of } \\
\text { transferable } \\
\text { competencies }\end{array}$ \\
\hline Aviation & $\begin{array}{l}\text { Crew resource } \\
\text { management } \\
\text { High-fidelity simulation }\end{array}$ & $\begin{array}{l}\text { Crisis resource } \\
\text { management } \\
\text { High-fidelity simulators } \\
\text { Unusual situations }\end{array}$ \\
\hline $\begin{array}{l}\text { Police and fire } \\
\text { departments }\end{array}$ & $\begin{array}{l}\text { Crime scene } \\
\text { reconstruction } \\
\text { Professional actors } \\
\text { Debriefing }\end{array}$ & $\begin{array}{l}\text { Conflict resolution } \\
\text { Simulation of victim } \\
\text { evaluation and triage } \\
\text { Death announcement } \\
\text { to family }\end{array}$ \\
\hline $\begin{array}{l}\text { Navigation and } \\
\text { high-reliability } \\
\text { organization }\end{array}$ & $\begin{array}{l}\text { Multimodal high-fidelity } \\
\text { simulations }\end{array}$ & $\begin{array}{l}\text { Simulation for a high- } \\
\text { stakes operational } \\
\text { environment }\end{array}$ \\
\hline Armed forces & $\begin{array}{l}\text { Decision-making } \\
\text { After-action review }\end{array}$ & $\begin{array}{l}\text { Command and control } \\
\text { team } \\
\text { Crisis management } \\
\text { Disaster management }\end{array}$ \\
\hline Humanitarian & $\begin{array}{l}\text { Stress management } \\
\text { Interaction of multiple } \\
\text { parties } \\
\text { Emotional debriefing }\end{array}$ & $\begin{array}{l}\text { Cultural aspects } \\
\text { Onsite simulation } \\
\text { Emotional debriefing }\end{array}$ \\
\hline
\end{tabular}

safe operations. ${ }^{9}$ The most recent high-fidelity simulators reproduce the pilot's or captain's cabin (ie, ship's bridge simulators) as well as machine rooms (engine room resource management) in an extremely realistic manner by integrating dynamic auditory, visual, and proprioceptive factors (eg, boat movements). ${ }^{7}$

\section{Military training: cost and environmental impact reduction}

Western armed forces have long used all sorts of simulators to assist with teaching techniques or procedures and the general training of future soldiers. Some simulators consist of simple task-trainers (firing simulator for the use of firearms) or computer-assisted teaching (driving various vehicles) and are mainly used in the basic training of individual soldiers. ${ }^{10}$ However, most military situations require the use of highly specialized equipment and consequently simulators of a higher caliber are needed, eg, a flight or armored tank simulator. The use of video and systematic debriefing of training sessions or missions (after-action review) reinforces the lessons. High-level simulators ultimately allow for training for major operations (war games) and the coordinated engagement of multiple units (using a unit and battle group simulator). For political, financial, and environmental reasons, the development and use of high-fidelity simulators has risen sharply over the past few years. Simulation has proven to be particularly useful for activities that have a significant environmental impact or require a perfect prior mastery of a specific skill (airplane chase, tank combat). Research is currently underway to develop decision-making skills in crisis situations, also through the use of simulators. ${ }^{11}$

\section{High-reliability organizations and industries: human error and safety}

The concepts of CRM and high-fidelity simulation have been applied in various technological areas that require high levels of security, including offshore oil platforms, chemical industries, nuclear reactors, and rail transport. ${ }^{12}$ In these domains, the interest in simulators rests in their ability to work on the concept of human error and to develop procedures and behaviors that improve safety. In addition, simulation allows for training and formation of administrators in charge of these types of emergency situations.

The application of the concept of CRM to offshore oil platform work dates from the 1990s and is based on the same principles as aviation, ie, teamwork, numerous human errors, and potential risk of accident with multiple victims. ${ }^{13}$ As a result, petroleum companies have developed training based on simulations and managing human factors. Evaluations such as the Cockpit Management Attitudes Questionnaire have helped to develop the Offshore Emergency Team Attitude Questionnaire which is specifically designed to analyze teamwork on oil rigs. ${ }^{13}$

After several nuclear reactor accidents between 1970 and 1980, the management of human factors took on considerable importance in this area as well. Several studies have shown that human error was the cause in $20 \%-65 \%$ of nuclear reactor accidents. ${ }^{14}$ A report from the Gesellschaft für Anlagen und Reaktorsicherheit, a German research organization in the area of nuclear reactor safety, highlights the fact that communication and coordination problems during stressful situations are responsible for the majority of human errors in nuclear reactor accidents. Current training programs apply the concepts of CRM to control rooms of nuclear reactors using high-fidelity simulators that reproduce the work environment. ${ }^{15}$

\section{Humanitarian organizations: teamwork in crisis situations}

Several humanitarian organizations have developed training based on elements of CRM and simulation. The International Diploma in Humanitarian Assistance, organized by the Center for International Humanitarian Cooperation, offers among its courses a team building and leadership model comprising 
notions designed to improve behavior, communication, leadership, and decision-making skills. ${ }^{16}$

The International Federation of the Red Cross and the Red Croissant (FICRCR) also offers a course based on teamwork and group dynamics within the framework of the field assessment and coordination team module. This course surveys notions of decision-making, leadership, and communication in crisis situations and conflict management. ${ }^{17}$

Simulation sessions on an even larger scale are also proposed within the framework of the FICRCR, with field training that allows staff to train under conditions similar to humanitarian missions or public health evaluations. ${ }^{18}$ Many humanitarian organizations also offer training modules that comprise simulations of hostage situations or armed conflicts, which allow them to train and test their teams before leaving for a country at war. The debriefing phase in such a module understandably has a large emotional component.

\section{Police and fire department services: stress management and decision-making}

The use of CRM or stress management concepts, as well as video and simulations, are becoming more and more frequent in the initial training of police agents and in the continuing education of intervention groups, eg, special weapons and tactics teams and special forces. ${ }^{19}$

Beyond task-trainers, in particular, firearms simulators, high-fidelity simulation also allows for the reconstruction of a crime scene so that evidence preservation, clue-finding, and other elements integral to the investigation can be practiced (Figure 1). Conflict management, decision-making under stressful conditions, the reaction to acts of violence or the arrest of a suspect, are also addressed by way of a specific debriefing centered on emotional and cognitive components. ${ }^{20}$ These simulations quite often use professional actors and dedicated scenarios.

Firefighters in North America, Canada, and Australia have also adapted programs of sensitization to CRM and utilize simulations in their continuing education for decisionmaking and teamwork training. ${ }^{21}$

\section{Discussion}

Simulators reproduce environments which, at the extreme, perfectly mimic work conditions by integrating visual, auditory, and/or tactile elements. Simulation sessions take place under the supervision of trained instructors. The simulations are based on pre-established scenarios and also provide a structured debriefing. Most of the modules apply the concept of simulation to large multidisciplinary teams that quite often contain different levels of decision-making. ${ }^{22}$ It is of note that systematically incorporating video as a teaching tool allows for a period of reflection which is very important in the cycle of experiential learning. ${ }^{23}$

The domains discussed have notable similarities with medicine, ie, teamwork, the risk for human error, and the need to be able to train collaborators in a highly specialized and safe environment. Medical education reforms, as well as the development of quality programs in health care systems, both designed to improve the quality of care and patient safety, reinforce the current interest in medical simulation. These elements explain the success of the implementation of the concepts of CRM and high-fidelity simulation. $^{24}$

The first high-fidelity medical simulations to be developed were in the domain of anesthesiology within the framework of operating room activity. They were inspired notably by work done in aviation based on the notion of the optimization of teamwork or the concept of CRM. High-fidelity simulators are now commonly used in anesthesia for crisis resource management training, response to unusual emergencies, eg, malignant hyperthermia, problematic airway management, and cardiac arrest, and even assessment or certification. ${ }^{25,26}$ Teaching strategies based on high-fidelity simulations have been also implemented in emergency medicine, and were originally designed for team training and patient safety. In 2000, after the Institute of Medicine published its report "To Err is Human," the American Society for Academic Emergency Medicine, American College of Emergency Physicians, American Board of Emergency Medicine, and National Patient Safety Foundation held a conference on medical errors in emergency medicine. ${ }^{27}$ Most simulation programs in emergency medicine retain the notions of human error, patient safety, and multidisciplinary team training. ${ }^{28-30}$ More recent publications have evoked the potential impact of high-fidelity simulation on behavioral skills, communication, and decision-making. ${ }^{31}$

From its start in anesthesiology, the use of patient highfidelity simulators expanded rapidly to include pediatrics, surgery, cardiology, obstetric, intensive care, and dentistry. In the last five years, simulation programs have also begun to encompass a growing number of domains in nursing education, ranging from critical care to community health care; there is particular interest in communication and cognition in this area, using different scenarios with simulated patients. $^{32,33}$ 


\section{Benefits of high-fidelity simulations in medical education}

High-fidelity simulators reproduce the working environment and serve as an educational risk-free tool. Simulation scenarios are mostly based on past events or real experiences (incident reports, technical troubles, previous situations) with a dynamic evolution over time. In this sense, simulation differs from simple role-playing and allows for the accurate analysis of behaviors, favors reflection, and enhances the decision-making skills of participants. ${ }^{34}$ For these reasons, high-fidelity simulators offer many advantages and have almost unlimited educational potential. ${ }^{1,2,35}$ High-fidelity simulation is in fact regularly used for evaluation and certification in anesthesiology and critical care. ${ }^{36}$

The impact of any simulation model remains difficult to evaluate but can be categorized using the four levels of Kirkpatrick's model. ${ }^{37}$ The first level assesses the reaction and the satisfaction of the participants after a simulation session. The second level measures the skills and competences acquired by the participants. These two levels are the most frequently evaluated outcomes in medical simulations. The third and fourth levels deal with the impact on the behaviors of the participants and on the outcomes for patients. These last two levels are more difficult to assess and therefore are infrequently evaluated in medical simulations.

\section{Applying nonmedical experiences to medicine}

Nonmedical simulations frequently involve highly technical environments with realistic ergonomic and technical instrumentation, such as in airplane cockpit simulators. This technical fidelity of simulation forces participants to engage in the scenario of the simulation. Likewise, in simulations for medical education purposes, sophisticated mannequins are equipped with computer programs, and pharmacological or physiological modeling creates a realistic situation. These elements help participants better comprehend the situation and possibly also retain the competencies learned. ${ }^{38}$

In addition to the above elements, the psychological fidelity of the simulation is an equally important factor in medical education. The correlation between the simulation and the planned objectives can be improved by using credible scenarios and by using facilitators to engage participants to achieve those objectives (Figure 2)..$^{38,39}$

Lessons learned from high-fidelity simulation in nonmedical domains can be used as translational teaching tools and to support the transfer of ideas or competencies, in addition to promoting external collaboration in teaching, psychology, and technical domains. ${ }^{34}$

For example, many simulation centers have aeronautical instructors on their educational teams. In addition, psychologists are also regularly present, which allows for refinement of the psychological debriefing, as well as behavioral analysis.

\section{Limitations of high-fidelity simulation in medicine}

One of the major limitations of medical simulation is directly related to the concept of artificially recreating an environment and clinical situation. In contrast with the aeronautical model, where a simulated flight may perfectly mimic a standard real flight, a medical simulation can never closely duplicate a real situation; a medical simulation is limited by interface realism as well as technical and financial limitations. Furthermore, the mathematical and computer modeling are less accurate for patient simulations because they cannot recreate all of the anamnestic, clinical, or emotional variables. ${ }^{35}$ Therefore, the medical scenarios are never totally transposable to clinical reality. This aspect of clinical external validity is rarely evaluated and analyzed, evidenced by the very few publications on this topic to date..$^{40}$

Another limitation to medical simulation is that it may induce distortion of perception and overgeneralization, and can reinforce unwanted behaviors, particularly when the levels of the simulation and related objectives are poorly matched to the participants. ${ }^{32,41}$ These potential pitfalls confirm the importance of adapting the educational tool to the defined objectives as well as to the target public. For example, the Federal Aviation Administration utilizes different levels of flight simulator fidelity according to the skills and competence levels of the trainees.

\section{Conclusion}

Simulators are teaching tools that are extremely variable and diversified. Different strategies designed to enhance education or training based on high-fidelity simulations can bring about brainstorming for new applications and collaborations across fields in the area of simulation. In the field of medicine, the benefits of simulation remain difficult to measure, both in terms of quality of care and impact on morbidity or mortality. Nevertheless, simulations in the military, maritime and aeronautical fields have shown to have a beneficial behavioral, financial, political, and/or environmental impact. Going forward, such endpoints could be incorporated into any new medical curriculum, in association with educational 
and clinical endpoints. Use of high-fidelity simulation is not limited to the medical field but has developed in a variety of nonmedical organizations as well. This article presents examples of simulations in nonmedical organizations and compares them with high-fidelity medical simulators.

\section{Disclosure}

This topic was presented in part at the Second Swiss Conference on Standardized Patients and Simulation in Health Care, Bern, Switzerland, September 9-10, 2010. Otherwise, the authors report no conflicts of interest in this work.

\section{References}

1. Gaba D. The future vision of simulation in healthcare. Qual Safety Health Care. 2004;13:i2-i10.

2. Fritz PZ, Gray T, Flanagan B. Review of mannequin-based highfidelity simulation in emergency medicine. Emerg Med Australas. 2008; 20:1-9.

3. Fanning RM, Gaba DM. The role of debriefing in simulation-based learning. Sim Healthc. 2007;2:115-112.

4. Thatcher DC. Promoting learning through games and simulations. Simul Gaming. 1990;21:262-273.

5. The CRM Standing Group of the Royal Aeronautical Society. Crew Resource Management. Royal Aeronautical Society, London. 1999. Available from: http://www.raes-hfg.com/reports/crm-now.htm. Accessed April 3, 2011.

6. Helmreich R, Merritt A. Error management: A cultural universal in aviation and medicine. In: Helmreich RL, Merrit AC, editors. Culture at Work in Aviation and Medicine. Arlington, VA: Ashgate; 1998.

7. Barnett M, Gatfield D, Pekcan C. A research agenda in maritime crew resource management. Proceedings of International Conference on the Team Resource Management Conference in the 21st Century. EmbryRiddle Aeronautical University, Daytona Beach, FL, October 23-24, 2003.

8. Helmreich R, Wilhelm J, Klinect J, Merritt A. Culture, error and crew resource management. In: Salas E, Bowers C, Edens E, editors. Improving Teamwork in Organizations. Hillsdale, NJ: Erlbaum; 2001.

9. Hetherington C, Flin R, Mearns K. Safety in shipping: The human element. J Safety Res. 2006;37:401-411.

10. Magee M. State of the field review: Simulation in education. Final report. Canadian Council on Learning, Alberta Online Learning Consortium Calagary, 2006. Available from: http://www.ccl-cca.ca/ pdfs/StateOfField/SFRSimulationinEducationJul06REV.pdf. Accessed April 3, 2011.

11. Zimmerman L, Burns CA, Sestokas JM. High-fidelity simulation/ mentoring system for general officers in high-stakes operational environments. Proceedings of the Interservice/Industry Training, Simulation, and Education Conference, Orlando, FL, November 26-29, 2007.

12. Flin R. CRM: Improving teamwork in high reliability industries. Team Performance Management. 2002;8:68-78.

13. Flin R. Crew resource management for teams in the offshore oil industry. Team Performance Management. 1997;3:121-129.

14. Moray N. Human performance. In: Moray N, B Huey, editors. Human Factors Research and Nuclear Safety. Washington, DC: National Academic Press; 1998.

15. Dietrich R, Jochum K. Language processing. Group Interaction in High Risk Environments. Berlin, Daimler, Benz Stiftung, 2001. Available from: http://www.daimler-benz-stiftung.de/cms/uploads/images/service/ publications/gihre_image-brochure.pdf. Accessed April 3, 2011.

16. Lupton-Bowers P. Teamwork in humanitarian missions. In: Cahill KM, editor. Basics of International Humanitarian Missions. New York, NY: Fordham University Press; 2003.
17. International Federation of Red Cross and Red Crescent Societies. Working on an FACT Team - group dynamics. In: Field Assessment and Coordination Team. Geneva, Switzerland: International Federation of Red Cross and Red Crescent Societies; 2002.

18. Elsharkawi H, Sandbladh H, Aloudat T, Girardau A, Tjoflåt I, Brunnström C. Preparing humanitarian workers for future disaster response: A Red Cross field training model. Humanitarian Exchange Magazine. 2010;46:45-47.

19. Le Scnaff C, Taugis J. Stress management for police special forces. J Appl Sport Psychol. 2002;14:330-343.

20. Heslen WF, Starkes JL. A new training approach to complex decision making for police officers in potentially dangerous interventions. J Crim Justice. 1999;27:395-410.

21. International Association of Fire Chiefs. Crew Resource Management. 3rd ed. Fairfax, VA: International Association of Fire Chiefs; 2003.

22. Naseer A, Eldabi T, Jahangirian M, Stergioulas L. Potential applications of simulation modeling techniques in healthcare: Lessons learned from aerospace and military. Proceedings of the European and Mediterranean Conference on Information Systems, Dubaï, United Arab Emirates, May 25-26, 2008.

23. Goodrow MS, Seropian M, Hwang JCF, Benchen B. Professional audio/video for clinical simulation. In: Kyle RR, Bosseau MW, editors. Clinical Simulation: Operations, Engineering and Management. Burlington, MA: Academic Press Elsevier; 2008.

24. Bradley P. The history of simulation in medical education and possible future directions. Med Educ. 2006;40:254-262.

25. Gaba D, Howard S, Fish K, Smith B, Sowb Y. Simulation-based training in anesthesia crisis resource management (ACRM): A decade of experience. Simul Gaming. 2001;32:175-193.

26. Loy G. Simulation in anesthesiology. In: Loyd GE, Lake CL, Greenburg RB, editors. Practical Health Care Simulations. Philadelphia, PA: Elsevier Mosby; 2004.

27. Biros M, Adams J. Errors in emergency medicine: A call to action. Acad Emerg Med. 2000;7:1173-1174.

28. Small S, Wuerz R, Simon R, Shapiro N, Conn A, Setnik G. Demonstration of high-fidelity simulation team training for emergency medicine. Acad Emerg Med. 1999;6:312-323.

29. McFetrich J. A structured literature review on the use of high fidelity patient simulators for teaching in emergency medicine. Emerg Med. 2006:23:509-511.

30. Bond W, Lammers R, Spillane L, et al. The use of simulation in emergency medicine: A research agenda. Acad Emerg Med. 2007;14: 353-364.

31. Wallin CJ, Meurling L, Hedman L, Hedegard J, Felländer-Tasi L. Target-focused medical emergency team training using a human patient simulator: Effects on behaviour and attitude. Med Educ. 2007;41: 173-180.

32. Bailey C, Johnson-Russell J, Lupien A. High-fidelity patient simulation. In: Bradshaw M, Lowenstein A, editors. Innovative Teaching Strategies in Nursing and Related Health Professions. 5th ed. Sudbury, MA: Jones and Bartlett Publishers; 2010.

33. Yeager ST, Gotwals B. Incorporating high-fidelity simulation technology into community health nursing education. Clin Simul Nursing. 2010;6: e53-e59.

34. Sauvé L, Renaud L, Kaufman D, Marquis JS. Distinguishing between games and simulations: a systematic review. J Educ Technol Soc. 2007; $10: 247-256$.

35. Maran N, Glavin R. Low- to high-fidelity simulation: A continuum of medical education? Med Educ. 2003;37 Suppl 1:22-28.

36. Kim J, Neilipovitz D, Cardinal P, Chiu M, Clinch J. A pilot study using high-fidelity simulation to formally evaluate performance in the resuscitation of critically ill patients: The University of Ottawa Critical Care Medicine, High-Fidelity Simulation, and Crisis Resource Management I study. Crit Care Med. 2006;34:2167-2174.

37. Kirkpatrick D, Kirkpatrick J. Evaluating Training Programs: The Four Levels. 3rd ed. San Francisco, CA: Berrett-Koehler; 2006. 
38. Alinier G. Developing high-fidelity health care simulation scenarios: A guide for educators and professionals. Simul Gaming. 2010;41:9-26.

39. Gray W. Simulated task environments: The role of high-fidelity simulations, scaled worlds, synthetic environments, and laboratory tasks in basic and applied cognitive research. Cogn Sci. 2002;2:205-227.
40. Issenberg SB, McGaghie W, Petrusa E, Gordon DL, Scalese R. Features and uses of high-fidelity medical simulations that lead to effective learning: A BEME systematic review. Med Teach. 2005;27:10-28.

41. Scerbo M, Dawson S. High fidelity, high performance? Simul Healthc. 2007;2:224-230.

Advances in Medical Education and Practice

\section{Publish your work in this journal}

Advances in Medical Education and Practice is an international, peerreviewed, open access journal that aims to present and publish research on Medical Education covering medical, dental, nursing and allied healthcare professional education. The journal covers undergraduate education, postgraduate training and continuing medical education including emerging trends and innovative models linking education, research, and healthcare services. The manuscript management system is completely online and includes a very quick and fair peer-review system. Visit http://www.dovepress.com/testimonials.php to read real quotes from published authors.

Submit your manuscript here: http://www.dovepress.com/advances-in-medical-education-and-practice-journal 